\title{
Comparison Between Fracture Mechanics and Local Approach Models for the Analysis of Shallow Cracks
}

\author{
U. Eisele, M. Seidenfuss and J.-M. Pitard-Bouet* \\ MPA, Universität Stuttgart, Germany \\ *EDF, 77250 Moret-sur-Loing, France
}

\begin{abstract}
This contribution shall introduce the application of the fracture mechanics and damage mechanics on flawed specimens by comparing the methods, especially with regard to the evaluation of shallow cracks.

The investigations introduced here were conducted on specimens removed from a segment of a shape-welded vessel made of $10 \mathrm{MnMoNi} 55$. Using round notched tensile specimens the required parameters were determined for the local approach model by Rousselier. Following this the local approach model was used for calculating the macroscopic failure behaviour of CT-specimens and three-point bending specimens with long and shallow cracks. The crack depth to width ratio of the CT-specimens was approx. $\mathrm{a} W=0.56$, that of the three-point bending specimens $\mathrm{a} / \mathrm{W}=0.55$ and $\mathrm{a} / \mathrm{W}=0.07$.
\end{abstract}

Using experimental results and numerical calculations on the basis of the damage model according to Rousselier it is possible to examine the influence of specimen geometry and a/W-ratio on the crack initiation value $J_{i}$ and the crack resistance curve. Thus an evaluation of fracture mechanics methods is possible.

The course of the multi-axiality of the stress state is a possibility of assessing the transferability of crack resistance curves. In calculating the multi-axiality during a running crack it is shown how the multiaxiality changes as a function of the crack propagation.

\section{INTRODUCTION}

The numerical assessment of the integrity of components and structures requires the development of approaches which deal with transferable parameters. Two different approaches to deal with this task are common.

First the elastoplastic fracture mechanics; also called ,global approach“. This approach is restricted to precracked structures. For ductile materials the calculation of the failure behavior is generally performed by means of crack initiation values and crack resistance curves on the basis of the $J$-integral, in many cases in conjunction with a second parameter, describing the multiaxiality of the stress state.

The quality of calculation the crack initiation strongly depends on the selected formulation of the initiation value. While knowing that parameters like $\mathrm{J}_{\mathrm{Ic}} / 1 /$ and $\mathrm{J}_{0,2} / 2 /$ are geometry and size dependent, it is shown that the physical crack initiation parameter $\mathrm{J}_{\mathrm{i}} / 3 /$ leads to quite accurate results when dealing with large cracks /4/.

Uncertainties exist also in the experimental and numerical determination of the J-integral of ductile materials $/ 5 /$. These uncertainties are due to the lack of accuracy of different simplifications and the general application limits of the J-integral (hyperelastic material behavior, no unloading).

Several problems occur when calculating a running crack on the basis of a $J_{R^{-c u r v e}}$. It is shown $15,6 /$ that 
the line integral proposed by Rice is no longer path independent when stable crack growth occurs and so an accurate calculation of $\mathrm{J}$ is quite difficult. Also the numerical simulation of crack growth causes problems on the background that the crack resistance curves applied are not independent of size and geometry 17,8/. The course of the multi-axiality of the stress state is a possibility of assessing the transferability of crack resistance curves $/ 9 /$, but there are still some uncertainties when doing this.

There are also difficulties in the assessment of the behaviour of shallow cracks in ductile materials because most testing standards show shallow cracks to be outside of the range of validity.

Due to these inadequacies new local methods of describing the ductile failure are introduced. The so called local approach or damage models $/ 10,11,12,13 /$ try to describe the micromechanical processes in the material which finally lead to fracture via continuum mechanics approaches. Since the stress and deformation state and thus also the state of damage generally depend on the location, only local values and approaches are applied. Then by means of the local consideration it is possible to determine the location of crack initiation as well as crack growth. Owing to their local formulation, damage models may be used for the calculation of cracked as well as notched or smooth components.

Several publications show the wide range of applicability of such models /14-19/. Different materials, different geometries and sizes as well as three dimensional crack propagation can be simulated with a high accuracy. First applications are also known for dynamic testing $/ 16 /$, thermalshock loading $/ 17 /$, warm prestress effect $/ 18 /$ and microstructure modelling $/ 19 /$.

\section{THEORY}

\subsection{Local Approach}

Metallographic investigations show that the failure behavior of the investigated material can be divided into three phases:

- formation of voids on nonmetallic inclusions due to inclusion fracture or decohesion of inclusion and matrix

- growth of voids with increasing deformation

- coalescence of the voids in consequence of formation of shear bands and small secondary voids. This process finally leads to macroscopic fracture.

It is the task of the damage models to describe one or several of these phases via a mathematical model. Damage models are almost exclusively used in finite element programs because of their local approach. However finite element programs need continuum mechanics material models for the description of macroscopic structures. So the aim of a damage model must be to describe the extremely discontinuous stress and deformation state in the area of inclusions and voids with a continuum mechanics approach. For the calculations introduced hereafter, the following models have been chosen to describe the three phases of crack initiation.

\subsubsection{Void Formation}

In literature many void initiation models are presented. In this models void initiation are dependent on stress state, strain state and the energy. The models can also be coupled with statistical approaches.

For the investigated material metallographical examinations show that it can be assumed that void initiation takes place at the onset of plastic deformation. For some other steels the same mechanism is reported in the literature $/ 20,21 /$. This means that no explicit initiation model is necessary. 


\subsubsection{Void growth}

If a material contains voids, the volume constancy under plastic deformation is inevitably lost. However, the von Mises material model which is generally used to calculate ductile materials assumes a homogeneous material and subsequently a volume constancy. In the von Mises model the portion of plastic deformation therefore only depends on the deviatoric stresses. There is no dependence on the hydrostatic stress. If a material contains voids, plastic deformation may occur in that area despite pure hydrostatic loading of the material volume, since at most a two-axial stress state is possible on the void surface which allows the material to yield.

Rousselier /11/ offers a yield function which considers the dependence of plastic deformation on the hydrostatic stress in the case of voids:

$$
\begin{array}{ll}
\Phi= & \frac{\sigma_{\mathrm{v}}}{\rho}+\sigma_{\mathrm{k}} \times \mathrm{D} \times \mathrm{f} \times \mathrm{e}^{\frac{\sigma_{\mathrm{m}}}{(1-\mathrm{f}) \sigma_{\mathrm{k}}}}-\sigma_{0}=0 \\
\mathrm{D} & =\quad \text { material independent parameter } \\
\mathrm{f} & =\quad \text { actual void volume } \\
\rho & =\text { material density } \\
\sigma_{\mathrm{k}} & =\text { material dependent parameter } \\
\sigma_{\mathrm{m}} & =\text { hydrostatic stress } \\
\sigma_{\mathrm{v}} & =\text { von Mises stress } \\
\sigma_{0} & =\text { actual yield limit }
\end{array}
$$

In the case of a void volume of zero, i.e. a material without voids, Rousselier's and von Mises yield functions are identical. However with increasing void volume $f$, the second term of equation 1 becomes larger and the dependence of the yield strength on the hydrostatic stress grows.

\subsubsection{Void coalescence}

Rousselier's void growth model contains also implicitely the process of void coalescence. If, at an existing stress state, a certain degree of damage is reached, the stresses will drop steeply with increasing strains. This steep drop is simulating the coalescence of the voids as is shown in figure 1 on the example of a smoothly notched round tension bar. The disadvantage of Rousselier's method is that the gradient of the stress drop is not high enough and the stresses do not decline to zero as in reality but only approach zero asymptotically. The residual stresses resulting from this insufficient drop in stress add up to a considerable numerical magnitude in the case of larger amounts of crack growth and falsify the calculated crack growth a great deal. In order to compensate for this disadvantage, an additional critical void volume $f_{c}$ was introduced $/ 22 /$. If the calculated void volume reaches this critical value $f_{c}$, the stresses are lowered to zero, i.e. material stiffness is put to zero and in this way crack growth is simulated. 


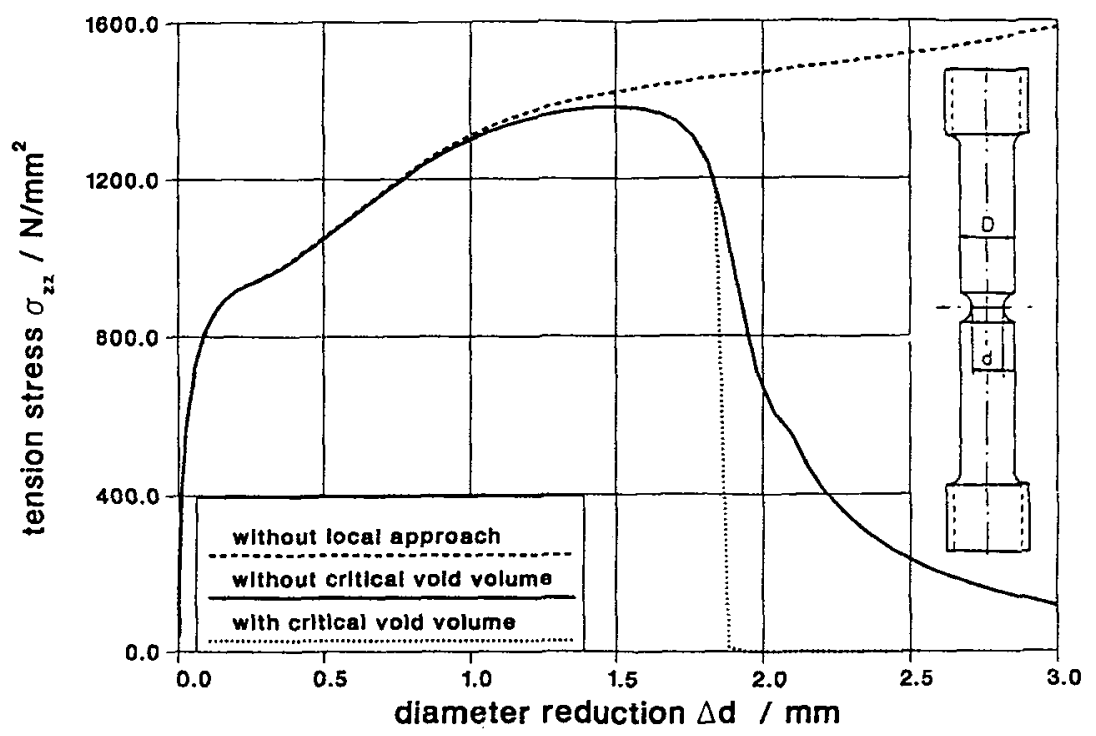

Figure 1: Stresses in load direction in the center of a round notched tensile bar

\subsection{Elastoplastic Fracture Mechanics}

For the engineering assessment of components with cracks methods of elastoplastic fracture mechanics are applicable as well.

In the fracture mechanics description of the failure mechanism, usually the stages up to and beyond crack initiation are considered.

The loading of the cracked component e. g. by external forces may be described with the J-integral which is calculated numerically by means of Rice's line integral.

Despite the limitations mentioned in the introduction the J-integral concept is usually applied to crack initiation and stable crack growth.

The effective crack initiation value $J_{i} / 3 /$ determined from the $J_{R}$-curve using the streched zone width measured in a scanning electron microscope is a transferable material value when dealing with large cracks and may be used to evaluate the crack initiation load. The local multiaxiality of the stress state was introduced as an additional parameter in order to be able to estimate the amounts of crack growth even after having exceeded the crack initiation load $/ 23 /$.

The multiaxiality of the stress state is for example expressed in the quotient $\mathrm{q} / 24 /$ :

$$
\begin{aligned}
& \mathrm{q}=\frac{\sigma_{\mathrm{v}}}{\sqrt{3} \sigma_{\mathrm{m}}} \\
\sigma_{\mathrm{v}} & =\text { von Mises stress } \\
\sigma_{\mathrm{m}} & =\text { hydrostatic stress }
\end{aligned}
$$


The multiaxiality quotient q may principally be determined for every location in a component by means of finite element calculations, because with the help of the finite element calculation the stress tensor is known at every point and the ratios of $\sigma_{\mathrm{v}}$ and $\sigma_{\mathrm{m}}$ may thus be computed.

Initiation occurs if $J=J_{i}$ and the $q$-value near the crack tip is equivalent to a critical value $q_{c}$. This critical value $q_{c}$ was defined by means of large-scale tests and numerical analyses as $q_{c}=0.28-0.3 / 25 /$.

Further crack growth (stable or unstable) results from two conditions:

a: $\mathrm{J}>\mathrm{J}_{\mathbf{i}}$

b: course of $\mathrm{q}$ (considered locally in the remaining ligament)

Now stable crack growth occurs if a minimum of q representing a maximum of multiaxiality exists near the crack tip and if the q-value increases with growing distance from the crack tip. Stable crack growth is then estimated by means of a $J_{R}$-curve determined using a specimen with the same course of $q$.

If there is a high and steady multiaxiality of the stress state, that is a small q-value, starting out from the crack tip and stretching over the whole ligament or at least over large parts of it, unstable crack growth meaning sudden fracture after exceeding the crack initiation load has to be expected.

\section{MATERIAL}

The examples presented in the following refer to the material $10 \mathrm{MnMoNi} 55$. This material is a high tough, shape welded steel $/ 26 /$. Former investigations $/ 26 /$ show that this material is highly isotropic and that material characteristics are independent of specimen orientation. The notch impact energy reaches values higher than $C_{V}=200 \mathrm{~J}$ in the upper shelf. The material characteristics for the investigated temperature (room temperature; beginning upper shelf of fracture toughness) can be taken from table 1 .

Table 1: Material characteristics, $10 \mathrm{MnMoNi} 5$, room temperature

\begin{tabular}{|c|c|c|c|c|}
\hline yield stress & $\begin{array}{c}\text { ultimate tensile } \\
\text { stress }\end{array}$ & $\begin{array}{c}\text { elongation at } \\
\text { fracture }\end{array}$ & reduction of area & Young's modulus \\
\hline $628 \mathrm{~N} / \mathrm{mm}^{2}$ & $708 \mathrm{~N} / \mathrm{mm}^{2}$ & $24.4 \%$ & $69.4 \%$ & $210000 \mathrm{~N} / \mathrm{mm}^{2}$ \\
\hline
\end{tabular}

\section{RESULTS AND DISCUSSION}

Initially the parameters needed for Rousselier's model were calibrated using metallographic and experimental results. The parameter used for the calculations presented in the following can be taken from table 2.

Table 2: damage parameters, $10 \mathrm{MnMoNi} 5$ 5, room temperature

\begin{tabular}{|c|c|c|c|c|}
\hline $\begin{array}{c}\text { initial void } \\
\text { volume } \mathrm{f}_{0}\end{array}$ & D-parameter & $\sigma_{\mathrm{k}}$-parameter & $\begin{array}{c}\text { critical void } \\
\text { volume } \mathrm{f}_{\mathrm{c}}\end{array}$ & $\begin{array}{c}\text { characteristic } \\
\text { length } \mathrm{f}_{\mathrm{c}}\end{array}$ \\
\hline .00001 & 2 & $445 . \mathrm{N} / \mathrm{mm}^{2}$ & 0.05 & $0.2 \mathrm{~mm}$ \\
\hline
\end{tabular}


The second step was to find out whether the damage parameters can be transferred to specimens of different size and geometry.

Figure 2 shows the load - diameter reduction behaviour of round tensile specimens with notches of diffe-

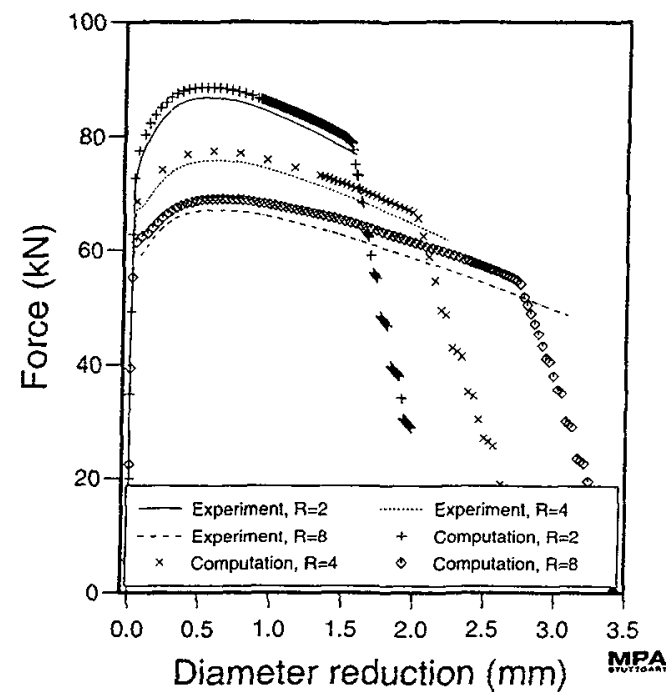

Figure 2: Comparison of measured and calculated load - diameter reduction behaviour of round tensile specimen, material $10 \mathrm{MnMoNi} 5 \mathrm{5}, \mathrm{T}=20^{\circ} \mathrm{C}$

rent radii. The lines show the experimentally determined behaviour and the points the numerical results. The good agreement between experiment and local approach calculation can clearly be seen in this figure. The calculation can show maximum load, fracture load as well as the point of instability.

In figure 3 is shown the load - crack mouth opening displacement (CMOD) behaviour of a $20 \%$ side-

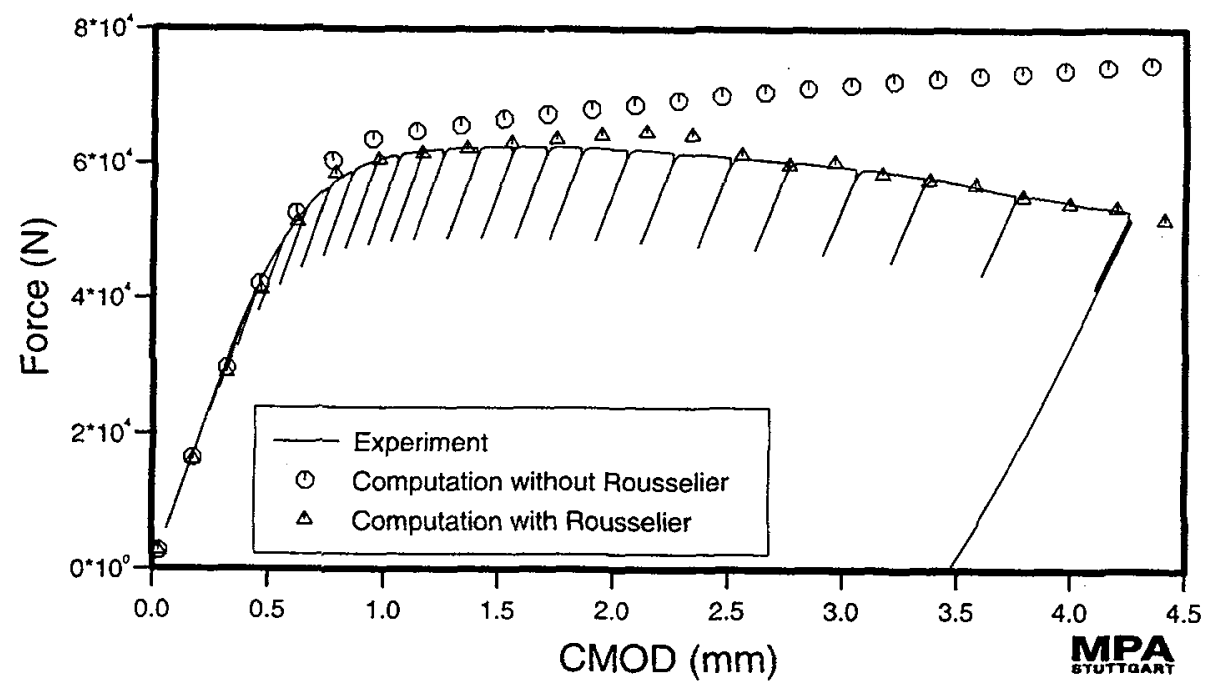

Figure 3: Comparison of measured and calculated load - CMOD behaviour of a $20 \%$ sidegrooved CT-25 specimen, a $\mathrm{W}=0.555$, material $10 \mathrm{MnMoNi} 55, \mathrm{~T}=20^{\circ} \mathrm{C}$ 
grooved CT25-specimen. The initial crack length $\mathrm{a}_{0}$ is about $27.75 \mathrm{~mm}$ or a/W $=0.555$. The solid line represents the experimental results, the empty points the values calculated with a common material model e.g. without taking crack growth into account. This numerical result highly overestimates the load with increasing deformation. The triangles in the picture give the numerical results calculated with the damage model. The agreement between damage calculation and experiment is quite good. The calculated crack growth from the damage model corresponds well with the experimentally determined one, figure 4.

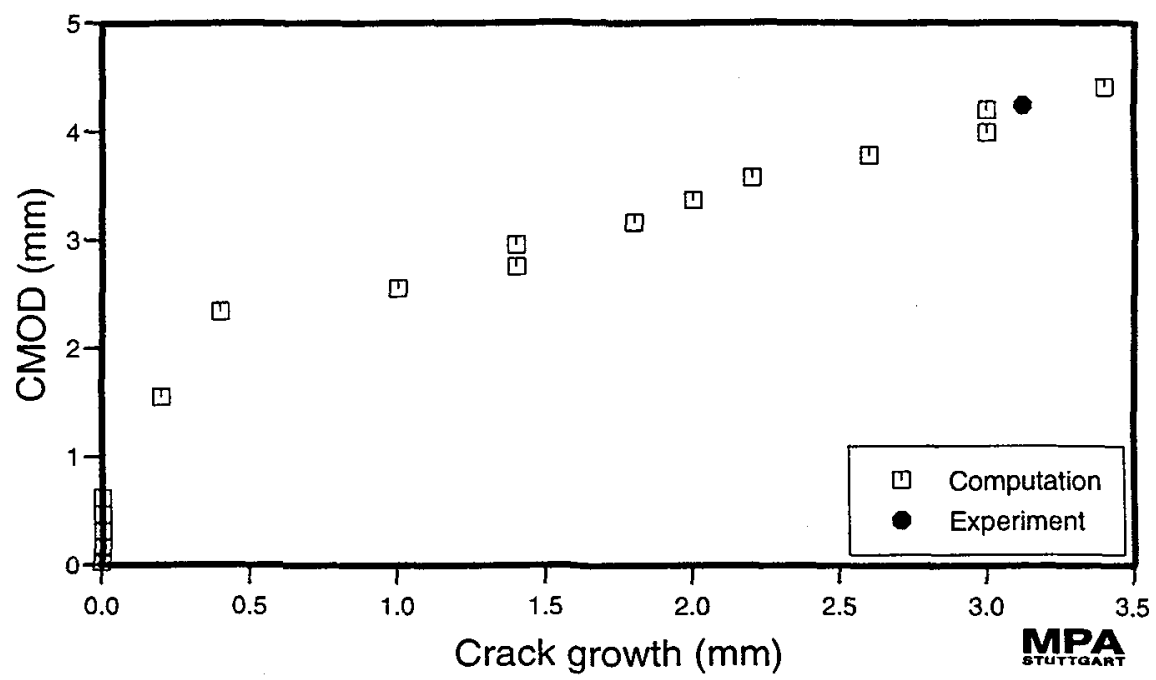

Figure 4: Comparison of measured and calculated CMOD - crack growth behaviour of a $20 \%$ sidegrooved CT-25 specimen, a/W $=0.555$, material $10 \mathrm{MnMoNi} 55, \mathrm{~T}=20^{\circ} \mathrm{C}$

The next step was to calculate three point bending specimen with a thickness of W $=25 \mathrm{~mm}$ (TPB-25 specimen). The selected specimens were $20 \%$ side-grooved. The deep cracked TPB- 25 specimen has a a/Wratio of 0.56 ; the specimen with the shallow crack shows $a / W=0.07$. In figure 5 and 6 the experimental

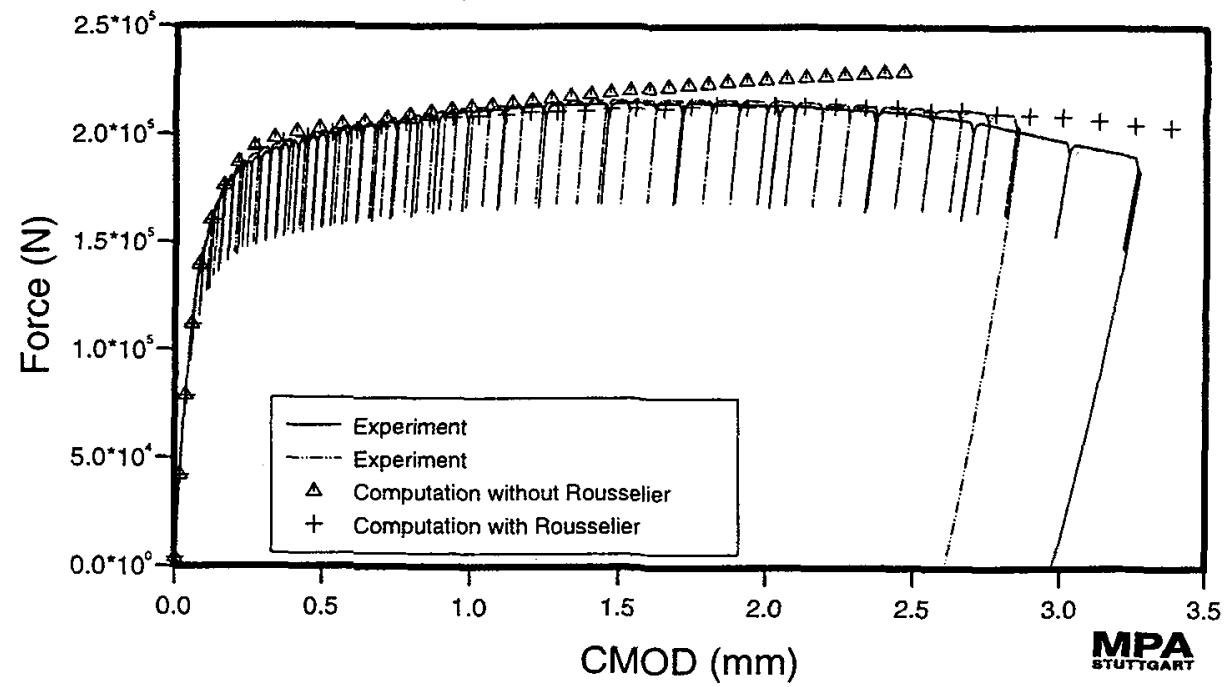

Figure 5: Comparison of measured and calculated load - CMOD behaviour of a shallow cracked 20\% sidegrooved TPB-25 specimen, $\mathrm{a} / \mathrm{W}=0.07$, material $10 \mathrm{MnMoNi} 55, \mathrm{~T}=20^{\circ} \mathrm{C}$ 
and the numerical load - CMOD behaviours for both crack lengths are presented. The calculations without damage model overestimate the experimentally measured load bearing capacity with increasing plastic deformation. As against this this the calculations with the Rousselier model are in good agreement with the experimental results for the deep cracked and the shallow cracked specimen.

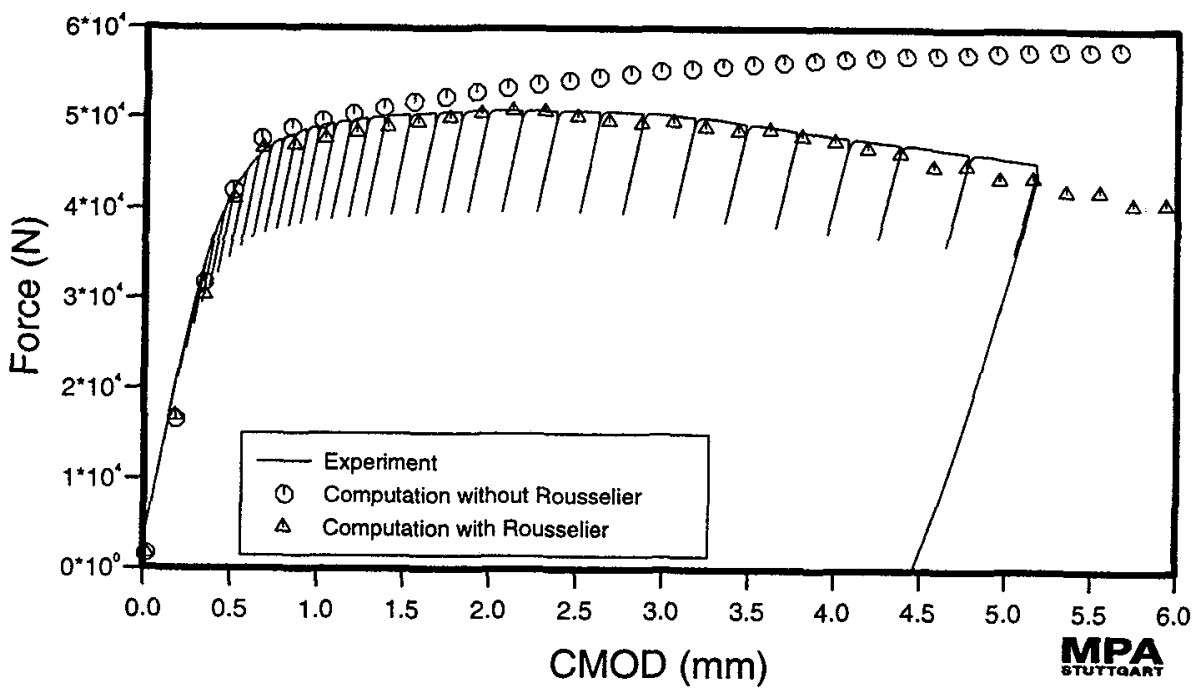
Figure 6: Comparison of measured and calculated load - CMOD behaviour of a $20 \%$ sidegrooved TPB-25 specimen,
a $\mathrm{W}=0.56$, material $10 \mathrm{MnMoNi} 55, \mathrm{~T}=20^{\circ} \mathrm{C}$

The crack growth behaviour of both specimen types can also be calculated by the damage model, figure 7 and 8.

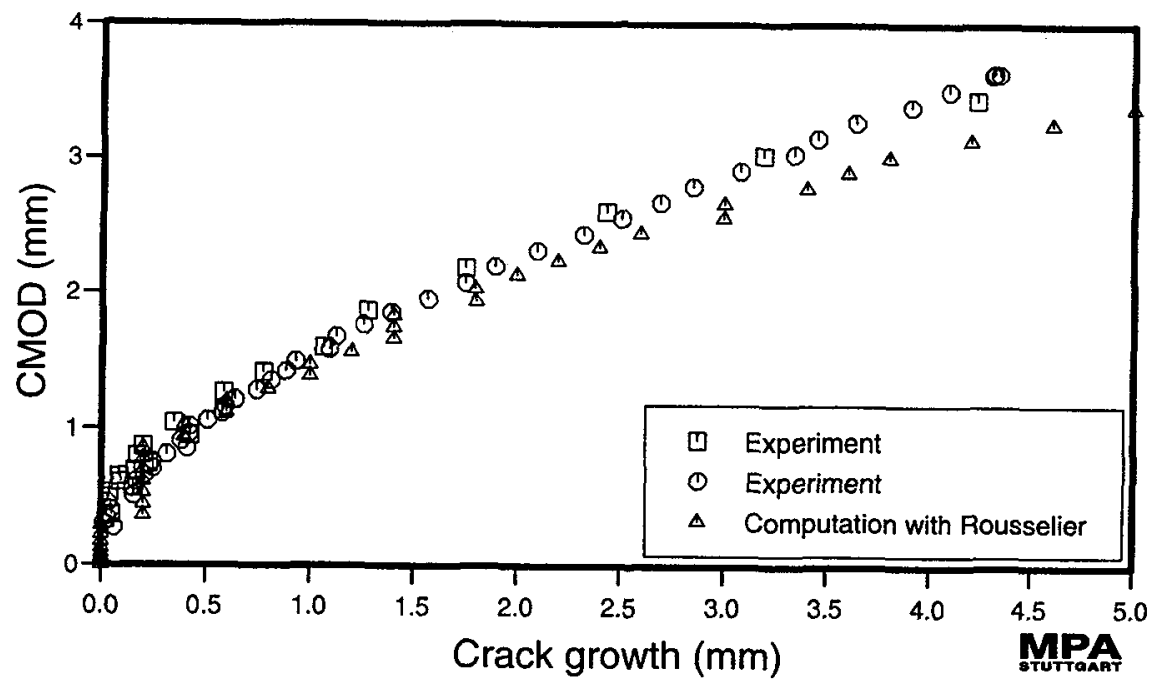

Figure 7: Comparison of measured and calculated CMOD - crack growth behaviour of a shallow cracked $20 \%$ sidegrooved TPB- 25 specimen, a $/ \mathrm{W}=0.07$, material $10 \mathrm{MnMoNi} 55, \mathrm{~T}=20^{\circ} \mathrm{C}$ 


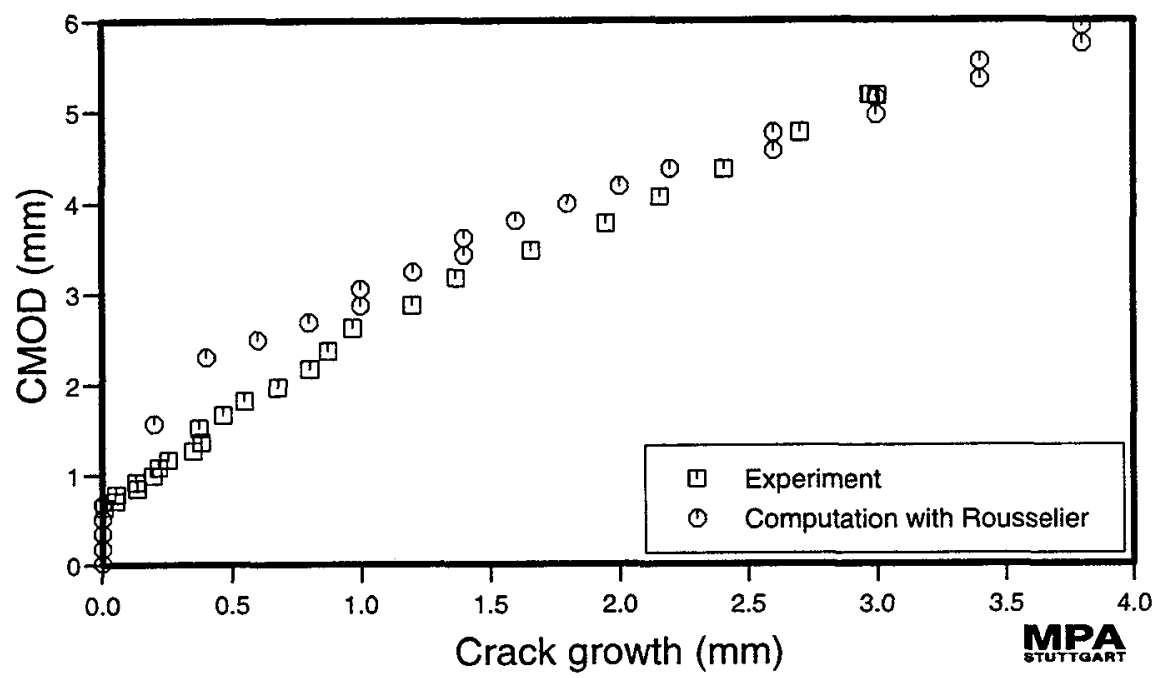

Figure 8: Comparison of measured and calculated CMOD - crack growth behaviour of a 20\% sidegrooved TPB-25 specimen, a/W $=0.56$, material $10 \mathrm{MnMoNi} 55, \mathrm{~T}=20^{\circ} \mathrm{C}$

Figure 9 shows experimental $\mathrm{K}_{\mathrm{Ic}}$-values and $\mathrm{K}_{\mathrm{J}}$-values calculated from experimental $\mathrm{J}_{\mathrm{i}}$ in dependence of the test temperature. It can be seen that in the transition region the $K_{J}$-values adapt well to the $K_{I c}-v a l u e s$.

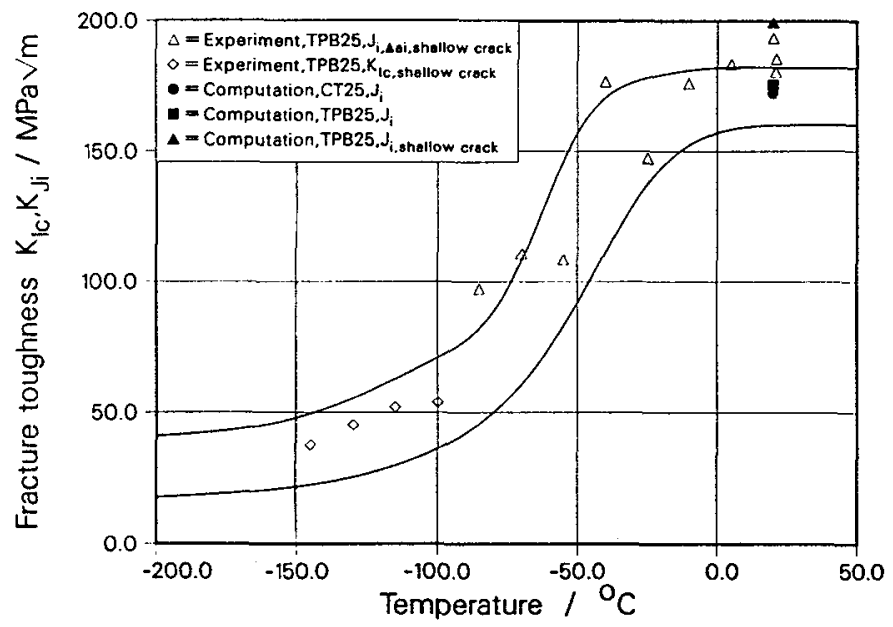

Figure 9: Experimental und numerical fracture toughness values, material $10 \mathrm{MnMoNi} 55$ 
In the upper transition and in the upper shelf the $\mathrm{K}_{\mathrm{J}}$-values elongates the $\mathrm{K}$-curve up to higher temperatures.

In order to compare these experimental values with numerical results it is assumed that numerical crack initiation takes place on reaching the critical void volume $f_{c}$ at the first Gauss point behind the crack tip. The comparison is made well knowing the fact that this numerical initiation value must not agree with the experimental one because of very different definitions.

Despite this limitation figure 9 shows that the numerical values fit quite well with the experimental scatter band.

For the shallow crack both, the experimental and the numerical initiation value are located in the upper part of the scatter band for ductile initiation obtained from deep cracked specimens. But the elevation of the shallow crack $\mathrm{K}_{\mathrm{J}}$-value is small compared with values from literature $/ 27 /$.

Regarding the whole experimental $\mathrm{J}_{\mathrm{R}}$-curves it can be seen that the slope following initiation is strongly dependent on geometry and crack length, figure 10. If the experimental curves are compared to the curves calculated with the damage model it is remarkable that the damage models can predict this geometry and crack length effect.

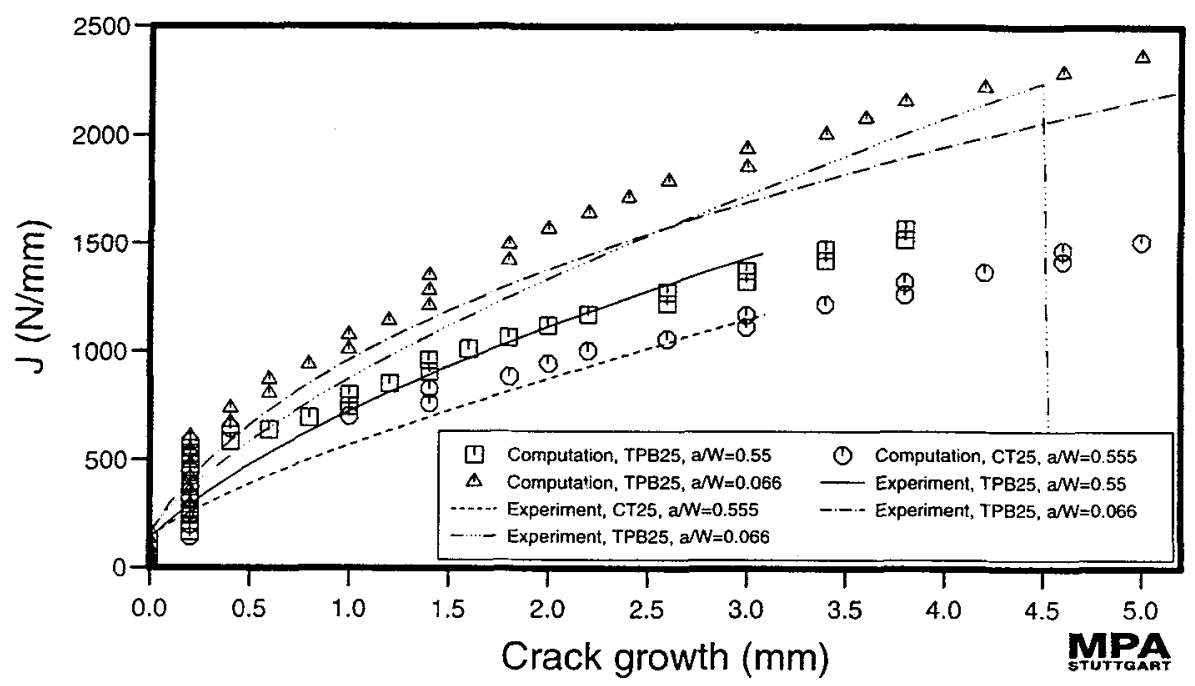

Figure 10: Experimental und numerical $\mathrm{J}_{\mathrm{R}}$-curves for different fracture mechanics specimen, material $10 \mathrm{MnMoNi} 55$

It can be concluded from the results presented above that it is possible to predict by means of the damage model the specimen behavior with size and geometry independent parameters.

As mentioned above the course of the multi-axiality of the stress state is a possibility of assessing the transferability of crack resistance curves. The idea behind this is, if component and specimen have similar

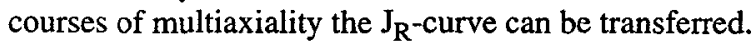

An additional calculation is made to compare the multiaxiality courses of the specimens. The damage model makes it possible to calculate high amounts of crack extension. Within a simulation a shallow cracked TPB specimen was loaded until crack growth leads to a similar crack length as measured at the deep cracked TPB-25 specimen. Because of this crack propagation up to $31 \mathrm{~mm}$ was simulated with the Rousselier model. As expected at the beginning the calculated load-CMOD behaviour corresponds well 
with the experimental one of the shallow cracked specimen, figure 11. On reaching the a/W-ratio of the

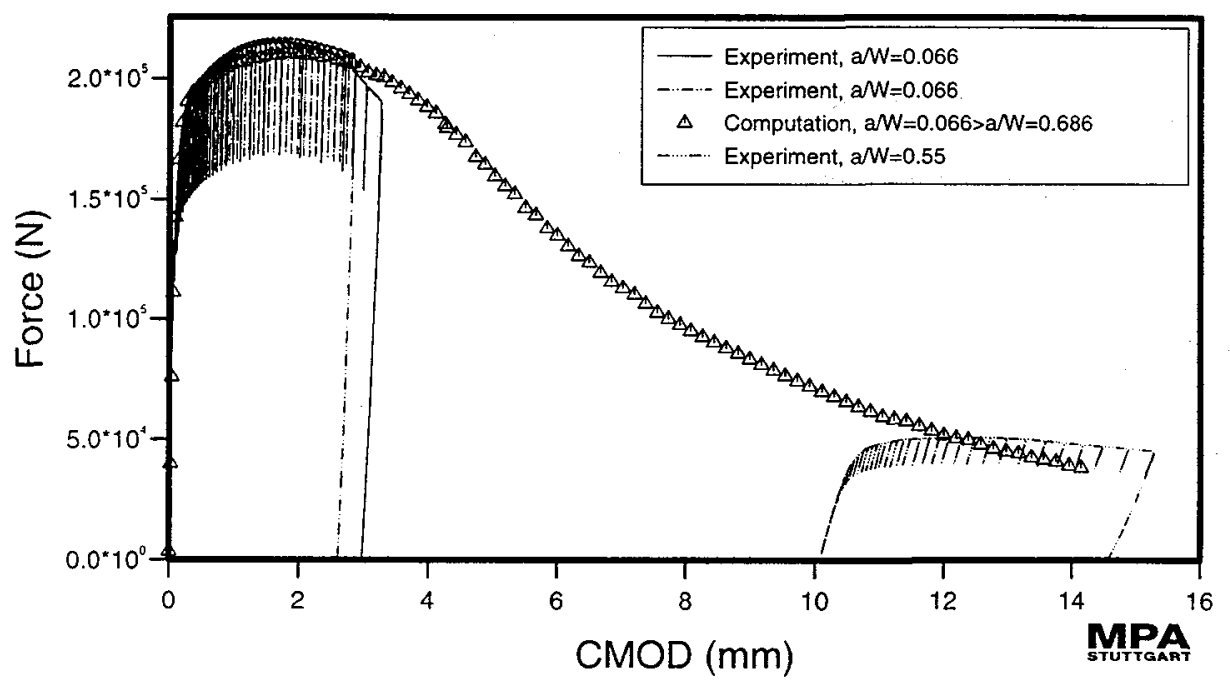

Figure 11: Comparison of calculated load - CMOD behaviour of a $20 \%$ sidegrooved TPB-25 specimen (a/W=0.07) with a large amount of crack growth with experimental values, material $10 \mathrm{MnMoNi} 55, \mathrm{~T}=20^{\circ} \mathrm{C}$

deep cracked specimen the numerical load-CMOD behaviour differs from the experiment with the correspondent a/W-ratio, figure 11 . A clear dependence of the deformation behaviour on loading history can be observed.

Figure 12 shows the q-courses at initiation load level of the three different specimens (CT-25, TPB$25 \mathrm{a} / \mathrm{W}=0.555, \mathrm{TPB}-25 \mathrm{a} / \mathrm{W}=0.07$ ), whereas the q-course of the CT25-specimen is only little flatter than the course of the deep cracked TPB-25 specimen; the shallow cracked one has significantly higher values.

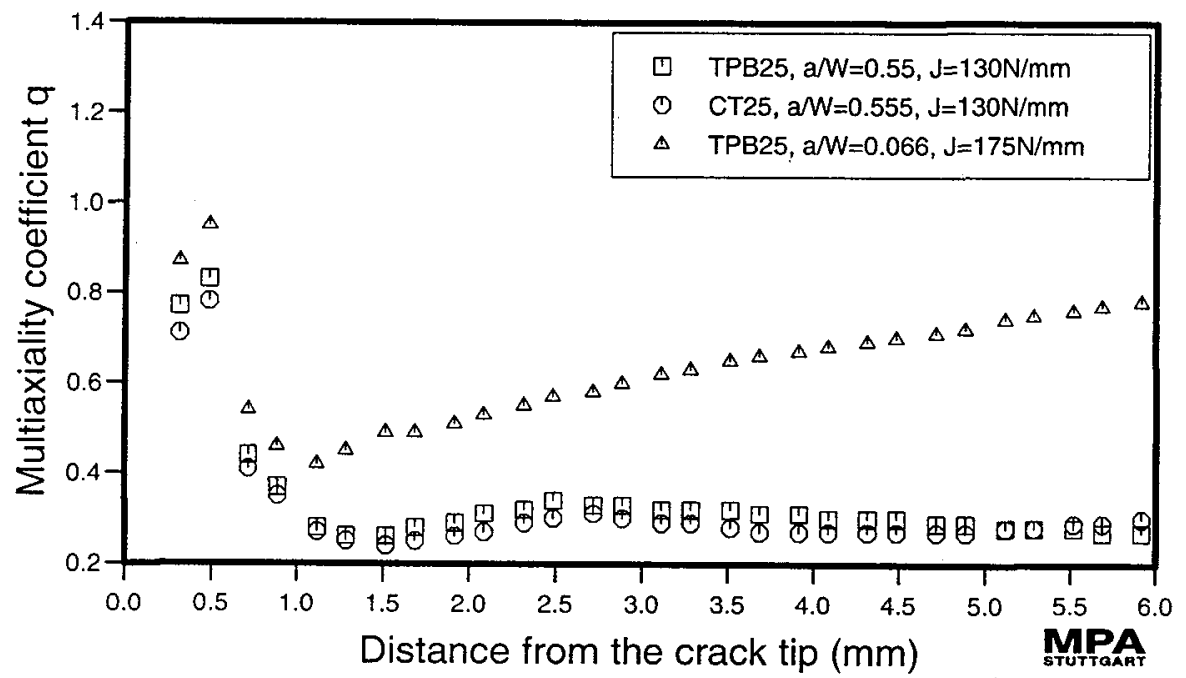

Figure 12: Calculated q-courses of different fracture mechanics specimen at crack initiation, material $10 \mathrm{MnMoNi} 55$ 
Simulating crack propagation until the shallow cracked specimen reaches a crack length $(\Delta \mathrm{a}=24.2 \mathrm{~mm})$ comparable to the deep cracked specimen and comparing at this point the q-courses it can be observed that the deviation between the specimens is significantly lower, figure 13. However, behind the q-minimum the calculation with the high amount of crack propagation shows a flatter q-course as the deep cracked TPB specimen though the actual a/W-ratio is comparable. Consequently when examining the failure behaviour of a specimen or a component it has to be distinguished whether a crack grows up to a certain a/W-ratio or whether the original crack initiates at this point.

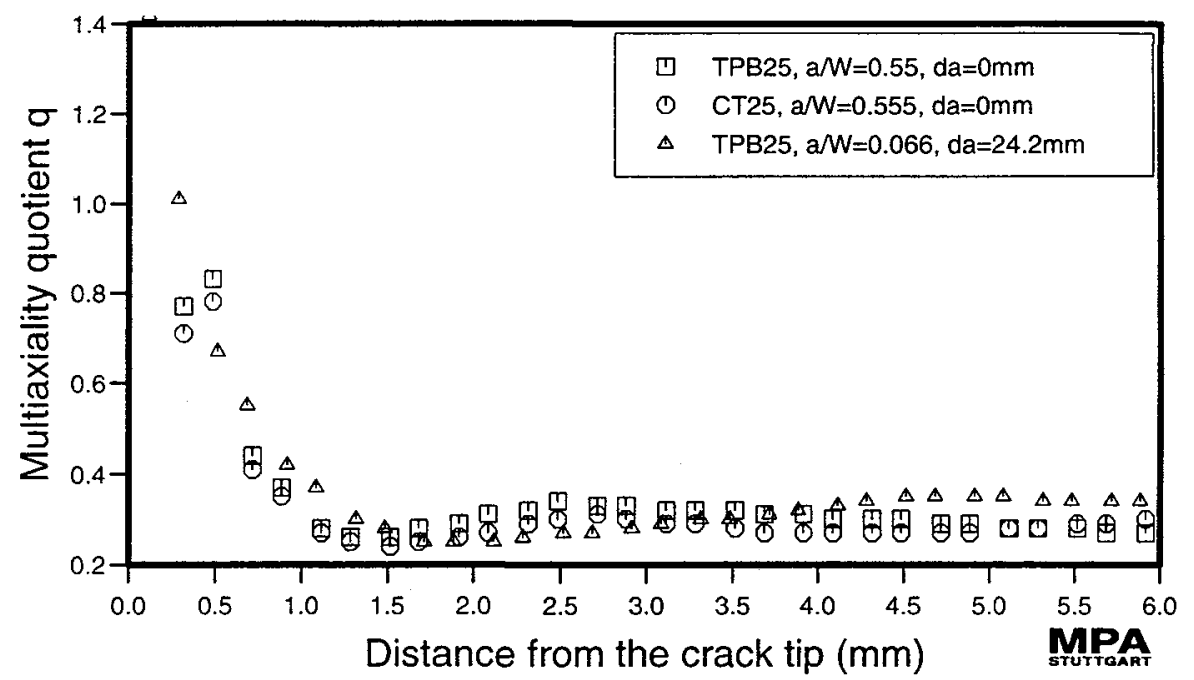

Figure 13: Calculated q-courses of different fracture mechanics specimen at a/W $=.55$, material $10 \mathrm{MnMoNi} 55$

If during calculation the variation of the q-course in dependence on crack propagation is observed, figure 14 and 15, it can be seen that with increasing crack length the q-course flattens. However, the variation of the q-course becomes smaller with increasing crack growth. Consequently, when transferring a $J_{R}$-curve from a specimen to a component not only the q-course at initiation must correspond but also the variation of the q-course during crack growth. 


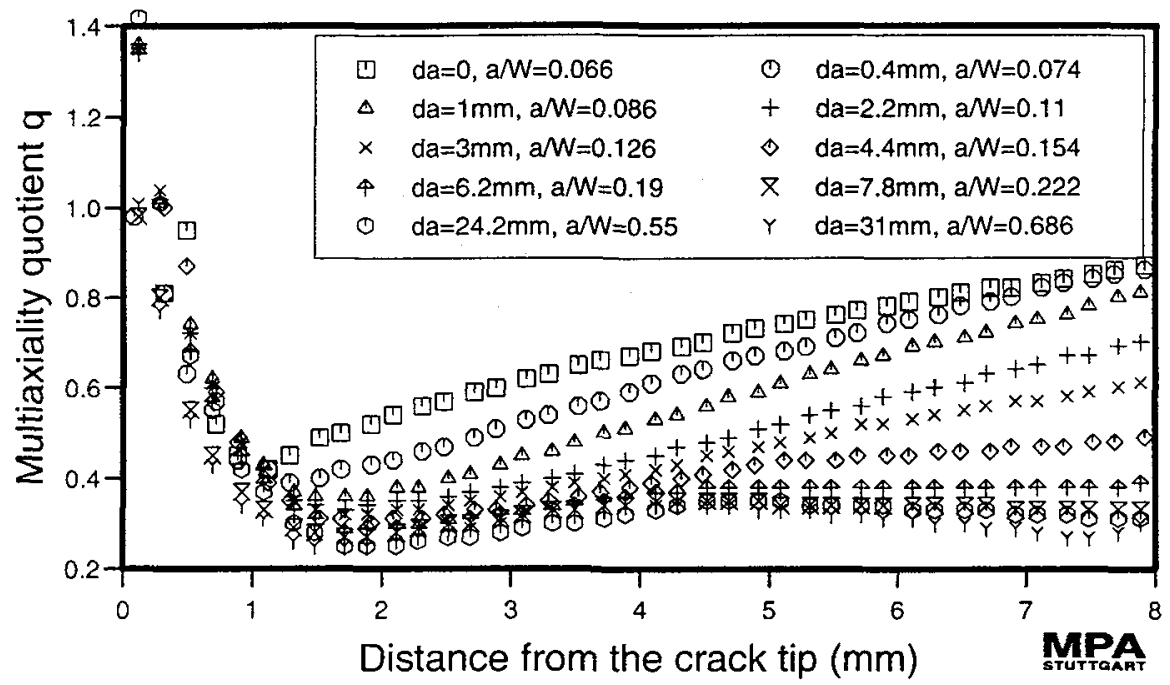

Figure 14: Calculated $q$-courses of the TPB-25 specimen $(\mathrm{a} / \mathrm{W}=0.07)$ for different amounts of crack growth, material 10 MnMoNi 55

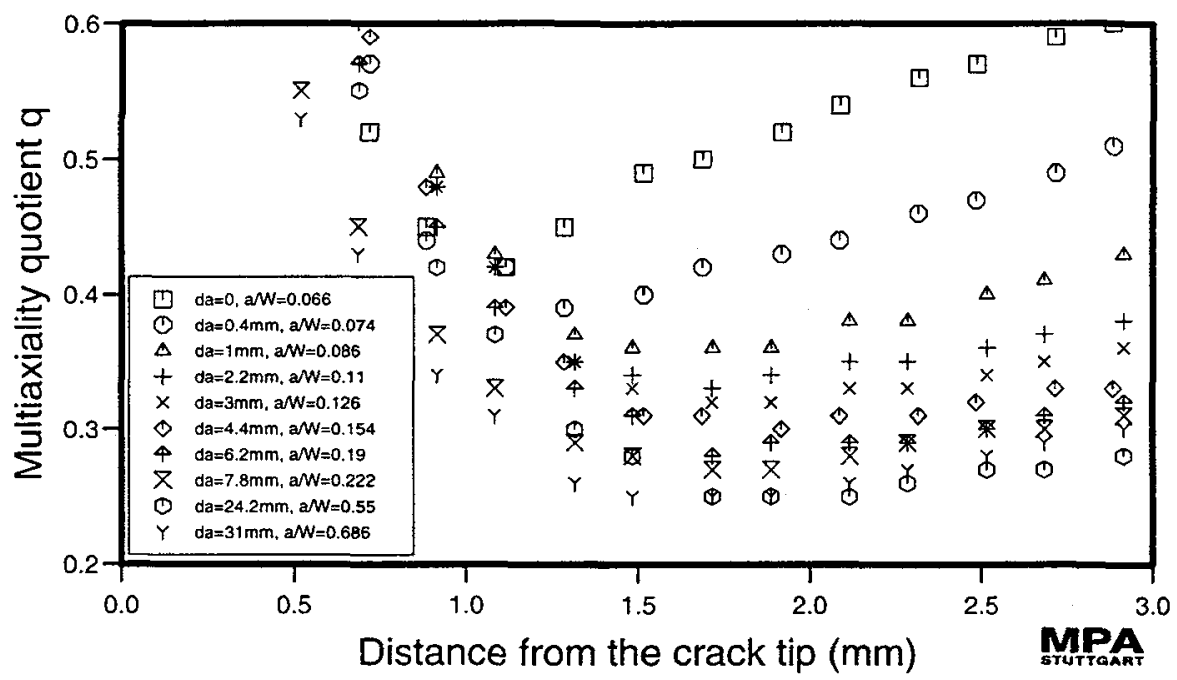

Figure 15: Calculated q-courses of the TPB-25 specimen $(a / W=0.07)$ for different amounts of crack growth, material $10 \mathrm{MnMoNi} 5$ 


\section{SUMMARY AND CONCLUSIONS}

The following conclusions can be drawn from the results presented in the paper:

- Using the damage model of Rousselier, the failure behaviour of round notched tensile bars can be calculated well. Global deformation behaviour, maximum load and instability can be simulated correctly.

- With the same model the failure behaviour of fracture mechanics specimens with deep cracks and shallow cracks can be described. Deformation behaviour and maximum load can be calculated as well as the stable crack growth.

- With the Rousselier model crack propagation up to $31 \mathrm{~mm}$ can be simulated when taking $\mathrm{f}_{\mathfrak{c}}$ into account.

- The parameters used for the calculation are transferable from the round notched bars to the highly different fracture mechanics specimens.

- At the investigated temperature (the beginning upper shelf of fracture toughness) the experimental initiation value corresponds well with the numerical onset of crack growth for all types of specimen.

- At the investigated temperature the initiation values (numerical and experimental) for the shallow cracked specimen are at or slightly above the upper bound of the scatterband obtained from deep cracked specimen.

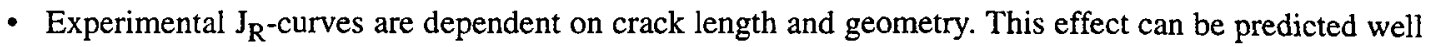
with the numerical model.

- As expected the different specimens show different q-courses at initiation.

- The q-courses differ if crack growth starts at a certain a/W-ratio or if this a/W-ratio results from considerable crack growth in the previous loading history. It has to be determined that the q-course differ significantly during crack growth when dealing with shallow cracks.

Finally it can be said that it is possible to predict the failure behaviour of specimens independent of crack length by means of the Rousselier model. The parameters used for the calculations are independent of geometry. The calculated and the experimental $J_{R^{-}}$curves are dependent on multiaxiality. When transfering $J_{R^{-}}$ curves on the basis of the q-courses it has to be taken into account that the courses can change during crack growth when dealing with shallow cracks or if larger amounts of crack growth are considered.

\section{REFERENCES}

/1/ ASTM E813-89, Standard test method for $\mathrm{J}_{\mathrm{IC}}$, a measure of fracture toughness.

12/ EGF P1-90, EGF recommendations for determining the fracture resistance of ductile materials, European Group on Fracrure, 1989.

13/ Roos E., Eisele U.: Determination of the material characteristic values in the elastic-plastic fracture mechanics by means of J-integral crack resistance curves, Journal of Testing and Evaluation, Vol. 16 No.1, 1988.

14/ Roos E., Eisele U.: Evaluation od different J-initiation values with regard to their usability in the safety assessment of components, Nuclear Engineering and Design 130, 1991.

15/ Roos E., Seidenfuss M., Krämer D., Krolop S., Eisele U., Hindenlang U.: Application and evaluation of different numerical methods for determining crack resistance curves, Nuclear Engineering and Design $130,1991$.

16/ Brocks W., Fricke S., Veith H.: Großes stabiles Rißwachstum in Bruchmechanikproben, 18th MPASeminar, 1992. 
17/ Roos E., Eisele U., Silcher H., Spaeth F.: The influence of the material toughness and the state of stress on fracture of large scale specimens, Nuclear Engineering and Design 102, 1987.

18/ Eisele U., Roos E., Seidenfuss M., Silcher H.: Determination of. J-integral-based crack resistance curves and initiation values for the assessment of cracked large scale specimens, Fracture Mechanics: 21 nd symposium Vol. 1, ASTM STP 1131, 1992.

19/ Clausmeyer H., Kussmaul K., Roos E.: Influence of stress state on the failure behavior of cracked components made of steel, Appl. Mech. Rev. Vol. 44 No. 2, 1991.

/10/ Beremin F. M.: Experimental and numerical study of the different stages in ductile rupture: application to crack initiation and stable crack growth, Three-dimensional constitutive relations and ductile fracture, North-Holland publishing company, 1981.

/11/ Rousselier G.: Ductile fracture models and their potential in local approach of fracture, Nuclear Engineering and Design 105, 1987.

112/ Gurson, A.L.: Plastic flow and fracture behavior of ductile materials incorporating void nucleation, growth and interaction, PhD thesis, Division of Engineering, Brown University, Providence, R.I., June 1975.

113/ Tvergaard V.: Influence of voids on shear band instabilities under plane strain, Int. journal on fracture vol. 17, 1981.

114/ Kussmaul K., Seidenfuss M., Eisele U.: On the applicability of damage models for the description of the failure behaviour of ductile steels ICF8 Conference, Kiev Ukraine, 1993.

/15/ Kussmaul K., Eisele U., Seidenfuss M.: On the applicability of local approach models for the determination of the failure behaviour of steels of different toughness, ASME PVP-Vol. 304, Fatigue and Fracture Mechanics in Pressure Vessel and Piping, 1995.

/16/ Sun D.-Z., Brocks W., Schmitt W.: Fracture toughness evaluation from tension and charpy type specimens based on micromechanical material models, ICF8 Conference, Kiev Ukraine, 1993.

/17/Bethmont M., Rousselier G., Kussmaul K., Sauter A., Jovanovic A.: The method of „local approach“ and its application to a thermal shock experiment, 14th MPA-Seminar, 1988.

/18/ Beremin F.M.: Numerical modelling of warm prestress effect using a damage function for cleavage fracture, ICF5 Conference, Cannes France, 1981.

/19/ Schmauder S.: Schädigungsmechanische Modellierung des mikrostrukturellen Versagens in Al/SiCVerbundwerkstoffen, 28. Tagung DVM-Arbeitskreis >Bruchvorgänge<, Bremen Germany, 1996.

120/ Arndt J., Dahl W.: Einfluß des Spannungszustandes auf die Mechanismen des Gleitbruchs, 28. Tagung DVM-Arbeitskreis >Bruchvorgänge<, Bremen Germany, 1996.

121/ Kussmaul K., Seidenfuss M.: Experimental and numerical investigations to describe the failure behaviour of steels of different toughness by means of damage models, BMFT Reactor Safety Research - Project No. 1500 913, 1995.

122/ Seidenfuss M.: Untersuchungen zur Beschreibung des Versagensverhaltens mit Hilfe von Schädigungsmodellen am Beispiel des Werkstoffes 20 MnMoNi 5 5, Dissertation an der Fakultät für Energietechnik der Universität Stuttgart, 1992.

123/ Eisele U., Herter K.H., Schuler X.: Influence of the multiaxiality of stress state on the ductile fracture behaviour of degraded piping components, Proceedings of ECF 10, Berlin, 1994.

124/ Clausmeyer H.: Über die Beanspruchung von Stahl bei mehrachsigen Spannungszuständen, Konstruktion 20 Heft 10, 1968.

/25/ Roos E., Eisele U., Silcher H.: Effect of stress state on the ductile fracture behavior of large scale specimens, ASTM Symposium on Constraint Effects in Fracture, ASTM 1171, 1993.

/26/ Schoch F.-W.: Eigenschaften formgeschweißter Großbauteile; Werkstoffuntersuchungen an einem 72t Versuchskörper aus Schweißgut 10 MnMoNi 5 5, Techn.-wiss. Ber. MPA Stuttgart, 1984.

/27/Sprock A.: Numerische Untersuchungen lokaler und globaler Kriterien für die Initiierung von duktilen Bruchvorgängen, Berichte aus dem Institut für Eisenhüttenkunde RWTH Aachen, Band 2/95, 1995. 